\title{
Processo de comunicação da informação em empresas de uma incubadora tecnológica
}

\author{
Marcio Gonçalves \\ Jornalista, mestre em ciência da informação pelo \\ Programa de Pós-Gradução em Ciência da Informação, \\ convênio MCT/Ibict - UFF. \\ E-mail: jornalistamarcio@ig.com.br
}

\section{Isa Freire}

Doutora em ciência da informação. Pesquisadora do IBICT e professora do Programa de Pós-Graduação em Ciência da Informação do convênio Ibict.

E-mailisa@ibict.br

\section{Resumo}

Apresenta os resultados de pesquisa-dissertação sobre o processo de comunicação da informação em incubadora de base tecnológica do Instituto Genesis da Pontifícia Universidade Católica do Rio de Janeiro. Discorre sobre o cenário atual das incubadoras no Brasil e no Rio de Janeiro, especificamente, discutindo a aplicação do modelo de gestão para incubadoras de empresas criado pela Rede de Incubadoras, Parques Tecnológicos e Pólos do Rio de Janeiro (ReINC), no que diz respeito ao módulo de informação. Aborda as questões da informação na perspectiva dos canais formais e informais de comunicação e da oferta e demanda de informação em incubadoras. Relata a participação da ciência da informação no mapeamento dos processos de comunicação da informação, destacando a importância da transferência de informação e da transformação desta em conhecimento.

\section{Palavras-chave}

Incubadoras tecnológicas. Canais de comunicação da informação. Transferência de informação. Ciência da Informação.

The process of information communication in technological incubator companies

\section{Abstract \\ This article presents results of a dissertation about the process of information communication in the technological incubator at Gênesis Institute of PUC-Rio. It describes an update scenario of incubators in Brazil and in Rio de Janeiro, to be more specifically, in order to discuss the application of a managing style for incubators designed by Relnc, related to an information model. The article also describes how information is applied in formal and informal channels of communication and information offering and demanding of information in incubators. It also approaches the Science Information role in mapping the process of information communication with a special participation of this science in information transfer and its transformation into knowledge.}

\section{Keywords}

Information Science. Incubators. Formal and informal channels of communication. Information transfer.

\section{INTRODUÇÃO}

Neste trabalho buscamos descrever e analisar o processo de comunicação da informação da Incubadora Tecnológica do Instituto Gênesis da Pontifícia Universidade Católica do Rio de Janeiro.

No tear da ciência da informação, iremos tecer um texto a partir dos fios conceituais de Araújo (1978), em sua abordagem dos canais formais e informais de comunicação da informação, e Freire (1991), na identificação de barreiras na comunicação da informação, que nos apoiaram na descrição desse processo em empresas de uma incubadora tecnológica; além de Barreto (1999), que nos auxiliou na análise dos dados coletados no campo da pesquisa, com sua proposição das unidades de transferência de conhecimento (UTC).

Nosso objetivo geral foi analisar o processo de comunicação da informação na Incubadora Tecnológica do Instituto Gênesis da Pontifícia Universidade Católica do Rio de Janeiro. Nesse processo, realizamos o levantamento dos recursos de comunicação disponíveis na Incubadora Tecnológica, verificamos os canais de comunicação mais utilizados na Incubadora Tecnológica, identificamos as barreiras no processo de comunicação da informação e mapeamos as necessidades de informação das empresas incubadas e das graduadas (que já passaram pelo processo de incubação).

Os resultados da pesquisa revelam que a ciência da informação tem nas incubadoras um campo para atuação de seus profissionais e que deveríamos incentivar os pesquisadores da área a conhecer melhor o que é uma incubadora de empresas, destacando-se o processo de comunicação da informação.

As incubadoras de empresas no Brasil e no Rio de Janeiro

O termo incubadora foi criado no século XX, no final da década de 1950, quando uma das maiores indústrias do estado de Nova Iorque fechou as portas. A falência desta indústria, que ocupava um galpão de quase 80 mil metros quadrados, contribuiu para elevar em até $20 \%$ a taxa de desemprego nessa região. Uma rica família local, liderada por Joseph Mancuso, buscou reverter o caótico quadro econômico: sua intenção era arrendar o espaço deixado 
por esta indústria a outra empresa que pudesse empregar a população e reacender o mercado daquela região. Lá pelos idos de 1959, a família de Mancuso desistiu dessa idéia e resolveu dividir o terreno para que várias pequenas empresas pudessem utilizar o espaço. Alguns serviços também seriam oferecidos e compartilhados pelas empresas. O curioso é que um aviário foi uma das primeiras empresas a se hospedar nesse espaço, conferindo, assim, ao prédio, o apelido de "incubadora" (CARVALHO; DIAS, 2002)

Paralelamente, porém, os autores observam que outros movimentos contribuíram para o surgimento de idéias semelhantes ao processo de incubação. Além dos condomínios de empresas, houve investimentos em programas de empreendedorismo e em novas empresas de tecnologia. Por iniciativa da National Science Foundation dos Estados Unidos, as maiores universidades da América do Norte iniciaram programas de empreeendedorismo e de geração de inovação em centros de pesquisa, envolvendo alunos e professores no processo de transferência dos conhecimentos das tecnologias produzidos na esfera acadêmica. Investidores, também, começaram a enxergar novas possibilidades de investimento de tempo e dinheiro em novos empreendimentos surgidos nestes ambientes de inovação.

Após o amadurecimento destes ambientes, o conceito de incubação e a proposta começam a se espalhar pelos Estados Unidos e Europa, passando a contar com estruturas mais bem estabelecidas. Como descreve Bermúdez (2000), um programa de incubadoras de

\footnotetext{
* Associação Nacional de Entidades Promotoras de Empreendimentos Inovadores. http://www.anprotec.org.br/ ** Serviço Brasileiro de Apoio às Micro e Pequenas Empresas. http:// www.portal.sebrae.com.br/.

*** Por iniciativa do professor Lynaldo Cavalcanti, presidente do CNPq à época, cinco fundações tecnológicas foram criadas: Campina Grande (PB), Manaus (AM), São Carlos (SP), Porto Alegre (RS) e Florianópolis (SC). Foi após a implantação da Fundação Parque de Alta Tecnologia de São Carlos, em dezembro de 1984, que começou a funcionar a primeira incubadora de empresas no país, considerada a mais antiga da América Latina, que possuía quatro empresas instaladas.
}

empresas normalmente coloca à disposição dos novos empreendimentos a instalação física, ou seja, o endereço do novo empreendimento, além de uma série de facilidades de escritório, como, por exemplo, computadores, redes, telecomunicações, secretárias, etc. Além destes itens, o glossário da Anprotec* e Sebrae** (2002, p.16) sugere que uma incubadora deve oferecer:

- ambiente flexível e encorajador;

- acesso a mecanismos de financiamento;

- acesso a mercados e redes de relações:

- processo de acompanhamento, avaliação e orientação.

Segundo histórico da Anprotec, no Brasil as primeiras incubadoras surgiram a partir da década de 1980.*** O I Seminário Internacional de Parques Tecnológicos, realizado em 1987, no Rio de Janeiro, veio a consolidálas. No mesmo ano, foi criada a Anprotec, órgão representativo das entidades gestoras de incubadoras de empresas, pólos e parques tecnológicos. Sua missão é representar e defender os interesses destas entidades, promovendo tais modelos como instrumentos para o desenvolvimento do país e objetivando a constante criação e fortalecimento de empresas baseadas no conhecimento (STAINSACK, 2003).
GRÁFICO 1

Distribuição regional das incubadoras brasileiras

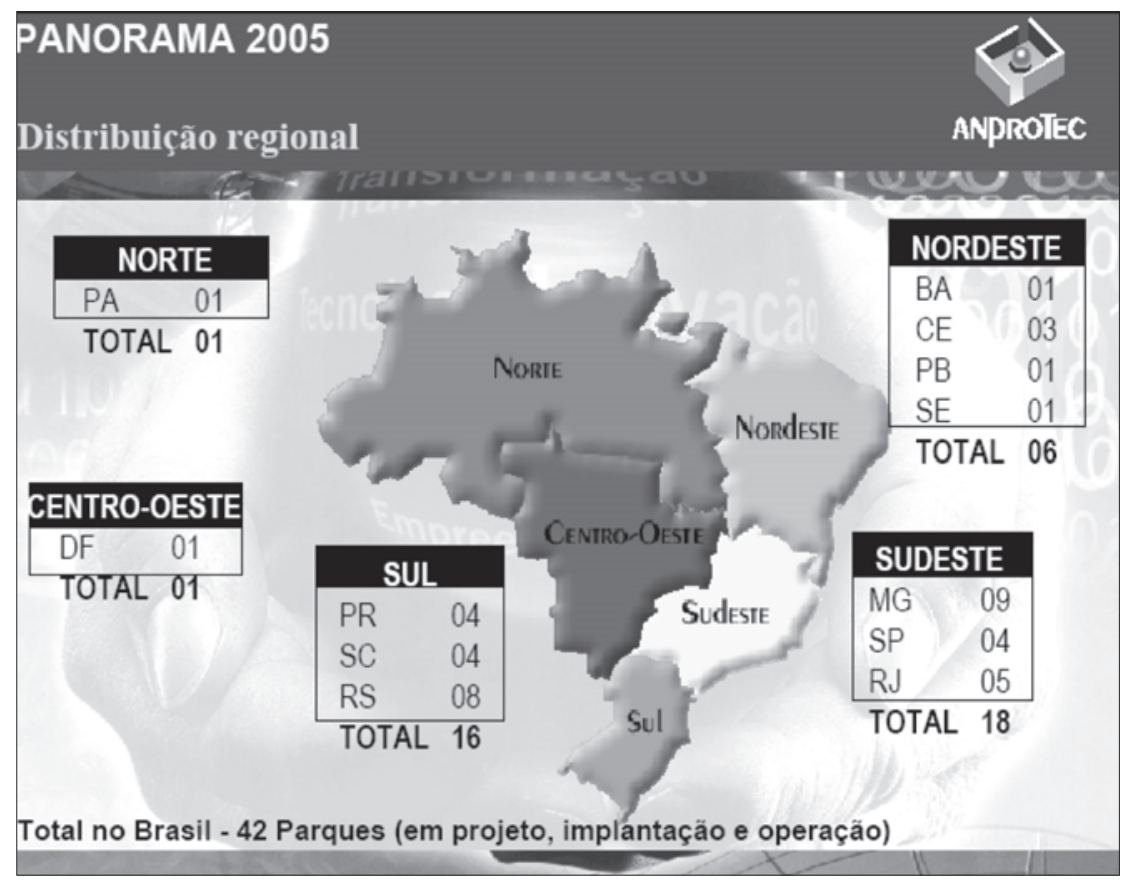

Fonte: Panorama 2005, Anprotec.

Ver informações sobre a imagem na página 18. 
Segundo o Panorama de Incubadoras de Empresas e Parques Tecnológicos, pesquisa realizada anualmente pela Anprotec em parceria com o Sebrae, em 2005 o número de incubadoras era de 339 , correspondendo a 2.327 empresas incubadas, 1.678 empresas graduadas e 1.613 empresas associadas, no total de 5.618 empresas. Uma forte concentração está nas regiões Sul e Sudeste, onde a atividade econômica brasileira está mais concentrada. A distribuição regional pode ser conferida no gráfico 1, página 17.

As incubadoras hoje contam com o apoio de instituições que se preocupam com o fomento do empreendedorismo. Essa iniciativa permite que elas tenham parâmetros mais concretos para avaliar sua performance como entidade mantenedora das empresas em processo de incubação. A ReINC* é uma das instituições que reúne as incubadoras sediadas no Rio de Janeiro. Ela se propõe a realizar projetos ligados à capacitação gerencial e ao desenvolvimento sustentável das empresas residentes nas incubadoras. O objetivo é estimular o aumento da capacidade "empreendedora", na realização de projetos conjuntos.

Em 2001, com apoio do Sebrae/RJ e da Prefeitura da Cidade do Rio de Janeiro/Secretaria de Desenvolvimento Econômico, Ciência e Tecnologia (Sedect), a ReINC publicou o Modelo de Gestão para Incubadoras de Empresas: uma estrutura de indicadores de desempenho,com objetivo de apresentar uma proposta concreta de modelos de gestão baseados em processos e indicadores aplicados às incubadoras de empresas do Estado do Rio de Janeiro.** Em 2002, dando continuidade ao projeto do Plano de Ação da ReINC no ano 2000, foi lançada a segunda publicação da série "modelos de gestão para incubadoras". Destacaremos aqui o módulo de informação, que tomaremos como referência para abordar o processo de comunicação da informação na Incubadora Tecnológica do Instituto Gênesis da PUC-Rio, inclusive empresas que fazem parte dela.

O módulo de informação inclui informações internas e externas e baseia-se na metodologia de CRM (Customer Relationship Management). O sistema utilizado deve

\footnotetext{
* Rede de Incubadoras, Parques Tecnológicos e Pólos do Rio de Janeiro com 18 incubadoras associadas, que totalizam 121 empreendimentos incubados e 100 graduados ou associados. Fonte: www.redetec.org.br.

** A Agenda das Cidades Empreendedoras e Inovadoras, publicada pela Anprotec em 2004, revela os municípios do Rio onde há incubadoras ou parques tecnológicos: Macaé,

Teresópolis, Rio de Janeiro, Piraí, Duque de Caxias, Angra dos Reis, Resende, Itaperuna, Seropédica, Vassouras, Petrópolis, Campos dos Goytacazes, Nova Friburgo, Volta Redonda e Niterói.
}

coletar, tratar, personalizar e distribuir as informações para os clientes na organização conforme a preferência e as demandas apresentadas pelos mesmos. Simões, Dias e Marujo (2002, p. 71-2) sugerem o módulo estruturado na forma de um sistema de informação cujos objetivos são os seguintes:

- facilitar a tomada de decisão: a organização da infra-estrutura da informação e da otimização da circulação das informações devem agilizar e facilitar o processo de tomada de decisão;

- possibilitar a retroalimentação do sistema: as informações devem ser tratadas de forma estratégica, por meio da personalização dos dados e da disseminação para os diferentes públicos, transformando-os em inteligência para o negócio;

- facilitar o compartilhamento de informações: este objetivo pressupõe a criação de canais de comunicação interno e externo, que podem ser a partir dos canais tecnológicos e dos tradicionais. Deve haver uma dinamização das formas existentes de elaboração de divulgação e de distribuição de informações, potencializando a geração de outras;

- favorecer o relacionamento com o cliente: o fornecimento de informações valiosas e em tempo real aos clientes, conforme sua preferência, a partir de critérios de coleta, tratamento e distribuição.

Segundo sua página na internet*, o Instituto Gênesis foi criado em julho de 1997, com o apoio de parceiros como o Citbank, o Serviço Brasileiro de Apoio a Micro e Pequenas Empresas (Sebrae), a Financiadora de Estudos e Projetos (Finep) e a Fundação de Amparo à Pesquisa do Rio de Janeiro (Faperj). No mesmo ano, com apoio da Softex** e do Departamento de Informática da PUCRio, iniciou-se uma pré-incubadora na área de informática, batizada de Infogene, e foram criadas três disciplinas de empreendedorismo nas áreas de comportamento, finanças e planejamento.

\footnotetext{
* http://www.genesis.puc-rio.br

** Associação para Promoção da Excelência do Software Brasileiro, responsável pela gestão do Programa Softex, um dos mais importantes instrumentos de apoio à produção e comércio do software brasileiro. Suas ações visam promover a competitividade da indústria de software, internet e comércio eletrônico no país e a qualificação de recursos humanos para o setor.
} 
Como o sugerido modelo de gestão resume-se a uma proposta desenvolvida e implantada em um projetopiloto na Incubadora Tecnológica do Instituto Gênesis (IG), da Pontifícia Universidade Católica do Rio de Janeiro (PUC-Rio), esta foi a incubadora escolhida como campo da pesquisa empírica.

\section{Uma abordagem da comunicação da informação}

Apresentado o cenário anterior, sobre as incubadoras como empreendimentos econômicos para o desenvolvimento social, trazemos agora a abordagem de Araújo sobre os canais formais e informais de comunicação da informação em ambientes tecnológicos. A autora define os canais formais como aqueles

cujas principais fontes de informação utilizadas são documentos, os quais de uma maneira geral podem ser classificados em literatura primária e literatura secundária (ARAÚJO, 1978, p. 9):

a) documentos ou literatura primária:

- periódicos: artigos, revistas, jornais técnicos;

- livros e monografias;

- dicionários, glossários e tesauros;

- diretórios;

- enciclopédias;

- relatórios: anuais, finais, técnicos, de atividades em andamento, de projetos;

- teses;

b) documentos ou literatura secundária:

- resumos;

- bibliografias;

- catálogos de publicações;

- traduções;

- revisões críticas: de literatura, do estado-da-arte;

- serviços automatizados: de índices, de resumos;

- alertas correntes (current contents);

- índices de citações (citation indexes);

- proceedings [anais] de eventos científicos.

A autora acrescenta que "as bibliografias, os dicionários e os glossários, os diretórios, as enciclopédias e os thesauri também são classificados como materiais de referência" (ARAÚJO, 1978, p.9). Já os canais informais são aqueles cujas principais fontes de informação são as pessoas. Isto significa que é utilizada a comunicação interpessoal.

Esses canais são altamente eficientes por permitirem a interação direta entre a fonte de informação e o usuário, minimizando assim o ruído. Envolvem basicamente a comunicação oral - conversas, discussões técnicas, discursos, conferências, telefonemas, bem como a comunicação escrita cartas, pré-impressos, etc. (ARAÚJO , 1978, p. 10)

A autora destaca as principais fontes de comunicação informal:

- colégios invisíveis - em ciência;

- rede de gatekeepers - em tecnologia;

- redes de comunicação intralaboratorial;

- redes de comunicação técnica/organizacional;

- comunicação pessoal: conversas, discussões técnicas, visitas, telefonemas;

- correspondência;

- feiras técnicas;

- congressos, conferências, convenções, seminários;

- encontros internacionais.

Vale ressaltar, ainda, a existência das mensagens eletrônicas ou e-mails. Se encarado como um documento que pode ser facilmente eliminado e sem condições de resgate da mensagem, podemos dizer que esse tipo de comunicação é considerado um tipo de canal informal. Entretanto, as mensagens eletrônicas também podem ser um canal formal, uma vez que oficializam e ratificam a troca de mensagens entre pares (ARAÚJO, 1978; FREIRE, 1991).

Araújo (1978) e Freire (1991) abordaram, pioneiramente, as barreiras à comunicação da informação em ambientes tecnológicos. No estudo de Araújo, são destacadas essas barreiras:

a) em laboratórios (de universidades, industriais para pesquisa e desenvolvimento, em institutos de pesquisa);

- comunicação inadequada com a comunidade de usuários (especialmente governo federal e estadual);

b) em pesquisa e desenvolvimento:

- falta de participação de consultores da universidade no setor produtivo;

- falta de síntese dos resultados de pesquisa e desenvolvimento;

c) nos grupos de usuários:

- há limitação da informação disponível sobre ciência e tecnologia;

- com freqüência, a informação disponível não é orientada para os usuários;

- a disseminação da informação é irregular e assistemática; 
d) quanto ao público, em geral:

- faltam identificação e reconhecimento de oportunidades para inovação;

- falta compreensão adequada dos benefícios e/ou conseqüências tecnológicas.

Em seu trabalho de identificação das barreiras na comunicação da informação tecnológica, a autora destaca os problemas que Wersig (1970) percebe como barreiras:

- ideológicas, seja entre países com formas diferentes de ordem social, onde diferentes ideologias orientam a vida social, ou entre grupos sociais em uma mesma sociedade, mas que possuem ideologias diferentes;

- econômicas, baseadas no fato de o conhecimento ter adquirido valor de propriedade privada para seu produtor, e sua publicação e uso dependerem do poder ou da negociação com o produtor;

- legais, representadas pelas restrições estabelecidas ao acesso e uso da informação, especialmente a informação tecnológica (aplicável à produção de bens e serviços);

- de tempo, seja pelo fato de a informação "envelhecer", tornar-se obsoleta como bem cultural ou de produção, o que obriga o usuário a estar atento à oferta de conhecimento, de modo a encontrar novos dados que complementem seu conjunto de informações; ou, porque, freqüentemente, muito tempo é gasto entre a produção da informação e sua disseminação por um meio de comunicação eficiente;

- de eficiência, tanto do ponto de vista do agente que transfere a informação (comunicador), que pode ser identificada na relação entre esforço para informar e usos/ efeitos da informação, quanto do ponto de vista do usuário, na medida dos esforços empreendidos para usar os serviços de informação (custos financeiros, tempo, estratégias de busca e outros esforços);

- financeiras, considerando que, como mercadoria, a informação tem um preço relativo aos seus custos e à demanda do mercado;

- terminológicas, pois nem sempre usuários e agentes de informação usam o mesmo código de linguagem no processo de recuperação do conhecimento, podendo ocorrer, especialmente na transferência de informação para o setor produtivo, que a terminologia utilizada dificulte a compreensão da mensagem pelos usuários finais;
- de idioma, que pode ser facilmente superada pela tradução para língua compreendida pelo usuário;

- de capacidade de leitura, que diz respeito à capacidade de o usuário selecionar o material informativo relevante para atender sua necessidade de informação, podendo ser superada pelo treinamento;

- de consciência e conhecimento da informação, o que significa para o agente atender à demanda apenas com informação conhecida ou ampliar suas fontes no limite da exaustividade;

- de responsabilidade, pois o uso da informação depende da atividade do usuário e de sua capacidade para fazer uso ativo do conhecimento técnicocientífico no seu trabalho.

\section{A abordagem de Barreto}

Em texto de 1999, Barreto descreve as unidades de transferência de conhecimento (UTC) como formalizadoras de um processo de transferência que permite completar o fluxo de conhecimento, a se realizar com a assimilação da informação pelo receptor e sua transformação em novo conhecimento. Ele descreve as duas funções básicas na gestão de uma UTC :

a) conhecimento e proposição de ações para disponibilizar estoques de informação;

b) comunicação da informação para promover o conhecimento e o desenvolvimento.

Neste contexto, identicamos na Incubadora Tecnológica do Instituto Gênesis um ambiente que apresenta as características descritas por Barreto (1999). Consideramos, nesse quadro de referência, o Instituto Gênesis como um "agregado de informação", cabendolhe produzir, armazenar e distribuir "estoques de informação” (BARRETO, 1996). Os estoques e sua distribuição estão relacionados, respectivamente, às condições de oferta e demanda da informação em determinado contexto. Se um estoque de informação produzido atende a uma demanda de informação, é porque, nesse momento, a incubadora estaria cumprindo o seu papel de produzir informação adequada aos empreendedores/usuários que a buscaram no processo de incubação, para agregar valor ao seu negócio. Em contrapartida, deve-se fazer valer a função de transferência efetiva e distribuição da informação estocada, de modo a promover uma oferta de informação que se antecipe à demanda dos empreendedores/usuários. 
Quanto às funções básicas de uma UTC, os gestores de incubadoras deveriam desempenhar as mesmas funções desta unidade, ou seja, conhecer e fornecer estratégias para disponibilizar estoques de informação ou ainda, realizar a comunicação da informação para promover o conhecimento e o desenvolvimento. Se os empreededores demandam informação, caberia à incubadora tecnológica oferecer, de forma sistemática, estoques de informação relevantes que os empresários/usuários possam transformar em conhecimento e desenvolvimento para suas empresas.

Para Barreto,

as unidades que operam os agregados de informação tendem a aumentar as suas condições de produção (volume do estoque) de maneira periódica e cumulativa, mesmo que não ocorra acréscimo na demanda por informação (BARRETO, 1999, p. 170,

grifo do autor). Desta forma, criam-se estoques de informação que servem para uso em outros estudos individuais ou em grupo ao longo da vida incubada ou até mesmo na incubação virtual. Quando refletimos sobre o que propõe Barreto, ao afirmar que a oferta de informação precisa estar em condições de atender a requisitos de qualidade, tais como

relevância, confiabilidade, cobertura, novidade e abrangências, a fim de disponibilizar seus produtos e serviços para o consumidor final” (Ibid, p. 170),

logo associamos o enunciado ao papel realizado pelas incubadoras. $\mathrm{O}$ papel do gerente da incubadora, assim, seria o mesmo que o de um gestor da informação.

Barreto observa que

o gerente não pode assumir a atitude econômica racional de só aumentar a oferta (acréscimo dos estoques), caso ocorra acréscimo da demanda, pois, a longo prazo, isto levaria à extinção daquela unidade (BARRETO, 1999, p. 170).

Seguindo a linha de pensamento do autor, concluímos que um gestor de uma incubadora, sobretudo as de base tecnológica, onde a informação parece ter mais demanda, deve buscar mecanismos para oferecer informação de forma a aumentar a eficiência dos processos produtivos e gerenciais nessas unidades. $\mathrm{O}$ autor reforça a idéia de que

sempre haverá necessidade de administrar estes estoques para um máximo de produtividade, o que tenderá a afetar a estratégia de distribuição da informação" (Ibid, p. 170).
Tomaremos esta abordagem como referência para entender o processo de comunicação entre a Incubadora Tecnológica do Instituto Gênesis da PUC-Rio e as empresas que fazem parte dela, na perspectiva dos canais formais e informais.

\section{O campo da pesquisa}

A pré-incubadora de informática tornou-se Incubadora Tecnológica Gênesis, com capacidade para 20 empresas residentes. O Projeto Gênesis tornou-se o Instituto Gênesis, unidade complementar da vice-reitoria acadêmica da PUC Rio, criado para coordenar não só o processo de préincubação e incubação, mas todo o Programa de Formação de Empreendedores (PFE) da universidade. A incubadora tecnológica possui foco em negócios da produção e distribuição de informação, privilegiando empresas que forneçam informações sob qualquer forma (verbal e sonora, impressa ou em vídeo) e que sejam inovadoras e intensivas em capital intelectual e tecnologia.

Os meios de comunicação disponíveis: (i) Panorama jornal bimestral com notícias da incubadora e das empresas, distribuído para parceiros e para dentro da PUC; (ii) portal do Instituto Gênesis (no caso da comunicação interna com as empresas, o canal usado é a extranet*, que publica uma newsletter enviada semanalmente às empresas); (iii) e-mail (para comunicados mais urgentes ou de interesse de pessoas específicas); (iv) encontros formais (p.ex., Conexão Gênesis) e informais (festas e outros eventos de integração).

\section{Metodologia aplicada ao campo da pesquisa}

Algumas questões orientaram nossa pesquisa de campo:

- O modelo do módulo de informação está sendo aplicado na Incubadora Tecnológica do Instituto Gënesis?

- Quais os recursos de comunicação da informação disponibilizados?

- Quais os canais de comunicação mais utilizados?

\footnotetext{
* Extranet é uma rede de acesso à intranet de uma empresa através de um portal (internet) estabelecido na Web, de forma que se consiga acesso à intranet por redes externas ao ambiente da empresa. O objetivo é melhorar a comunicação entre funcionários e parceiros, além de acumular uma base de conhecimento que possa ajudar os funcionários a criar soluções. Fonte: http://pt.wikipedia.org/wiki/Extranet. Acesso em 11/08/2006.
} 
- Quais as barreiras existentes no processo de comunicação da informação?

- Quais as necessidades de informação das empresas incubadas?

Investigamos o campo da pesquisa utilizando a observação direta intensiva, com técnicas de coleta de dados por observação e entrevista.

Segundo Marconi e Lakatos (2002, p. 88), a observação desempenha importante papel no contexto da descoberta, obrigando o pesquisador a um contato mais direto com a realidade e sendo considerada "o ponto de partida da investigação social”. Para as autoras, a observação oferece uma série de vantagens e limitações, havendo por isso necessidade de aplicar mais de uma técnica ao mesmo tempo (o que fizemos, com a entrevista). As vantagens são as seguintes:

- possibilidade de usar meios diretos e satisfatórios para estudar ampla variedade de fenômenos sociais, bem como de coletar dados sobre um conjunto de atitudes comportamentais típicas;

- menor exigência do observador em relação a outras técnicas;

- menor dependência da introspecção ou reflexão;

- possibilidade de encontrar evidência de dados não previstos no roteiro de entrevistas ou questionários.

As limitações da técnica de observação, segundo as autoras, são decorrentes da tendência dos observados para criar impressões favoráveis ou desfavoráveis no observador; ou da ocorrência de fatos não presenciados pelo observador; ou de fatores imprevistos que podem interferir na tarefa do pesquisador; ou da variabilidade na cronologia dos acontecimentos; ou, mesmo, de aspectos da vida cotidiana que podem não ser acessíveis ao pesquisador.

Outra técnica que utilizamos em complemento à observação foi entrevista, definida por Marconi e Lakatos como

um encontro entre duas pessoas a fim de que uma delas obtenha informações a respeito de determinado assunto, mediante uma conversação de natureza profissional. A entrevista constitui importante instrumento de pesquisa em vários campos das ciências sociais, sendo considerada "o instrumento por excelência da investigação social" (MARCONI e LAKATOS, 2002, p. 92-93).

Na nossa pesquisa, ela teve como metas:

- averiguar fatos, como, por exemplo, as fontes e os canais de comunicação da informação mais utilizados pelas empresas incubadas ou graduadas pela Incubadora Tecnológica do Instituto Gênesis;

- identificar opiniões sobre fatos, como, por exemplo, os benefícios do processo de incubação e as informações mais úteis para os negócios;

- determinar os sentimentos dos entrevistados com relação à IT.

Para realizar essas pretensões, em consonância com os objetivos da pesquisa, utilizamos uma entrevista estruturada, isto é, seguindo um roteiro preestabelecido. $O$ roteiro estruturado permite que as respostas dos entrevistados

sejam comparadas com o mesmo conjunto de perguntas, e que as diferenças [possam] refletir diferenças entre os respondentes e não diferenças nas perguntas (LODI, 1974, citado por MARCONI e LAKATOS, 2002, p.94).

Procuramos empresas incubadas e graduadas (que passaram pelo processo de incubação) para a realização das entrevistas com os empreendedores da incubadora tecnológica. Nosso objetivo ao investigar empresas graduadas foi o de acompanhar o processo de incubação das empresas que ainda estão ligadas ao Instituto Gênesis. Para angariar a participação dos empreendedores, elaboramos um convite feito por telefone mensagem eletrônica (e-mail) às 14 empresas residentes na Incubadora Tecnológica até o início da pesquisa, bem como para algumas já graduadas*. Houve retorno de três empresas residentes e de duas graduadas.

Mostra-se, a seguir, o roteiro de entrevista utilizado para facilitar o diálogo com os empreendedores:

- Há quanto tempo a empresa está incubada?

- Quanto tempo a mais pretende ficar incubada?

- Qual o motivo de ser incubada?

- Que benefícios tem com a incubação?

- Que canais utiliza para obter informações sobre o mercado?

* Empresas que passaram pelo processo de incubação e estão atuando no mercado. 
- Quais os canais mais utilizados?

- A incubadora tecnológica tem contribuído para isso?

- Quais canais de comunicação disponibilizados pela Incubadora Tecnológica você conhece?

- Considera as informações divulgadas nestes canais úteis para o seu negócio?

- Que tipo de informação considera útil para o seu negócio?

- De que outras fontes se utiliza para obter informações úteis para o seu negócio?

- Identifica alguma barreira na transferência da informação da incubadora tecnológica para as empresas residentes?

A seguir, ressaltamos os resultados das variáveis diretamente relacionadas ao processo de comunicação da informação.

\section{Resultados da pesquisa}

Na descrição das informações obtidas, transcreveremos trechos qualitativos considerados ilustrativos para a pesquisa. Os nomes dos entrevistados e a razão social da empresa serão preservados. Para facilitar o entendimento, decidimos separar as empresas participantes por ramo de atuação e descrição do seu negócio. Usaremos a nomenclatura de empresa alfa, beta e gama para cada uma das empresas ainda em processo de incubação; para as empresas graduadas, usaremos delta e ômega.

A empresa alfa é responsável pelo desenvolvimento de soluções de Data Quality para todas as etapas do marketing de relacionamento. Está em processo de incubação há dois anos e meio, com expectativa de mais um ano e meio. O entrevistado apontou "contatos, imprensa especializada e os informes da incubadora" como os meios mais utilizados para se manter informado. Ele acredita que a incubadora tecnológica tem proporcionado o acesso à informação necessária ao desenvolvimento do seu negócio, "tanto através de informes sistemáticos quanto da interação com empresas e pessoas proporcionada pelo cluster que é a incubadora". Dos canais de informação, a empresa alfa conhece os "informes semanais por e-mail, eventos/palestras, relatórios periódicos e comunicados de oportunidade". O empreendedor diz utilizar com mais freqüência os informes semanais e os comunicados de oportunidade, e considera úteis as informações divulgadas nesses canais. Para ele, "não fosse por isso não teríamos tomado conhecimento de coisas tão importantes e díspares quanto editais de fomento e reduções de alíquotas de impostos". O contato com pessoas do mercado foi outra fonte utilizada para obter informações úteis à empresa.

A empresa beta provê soluções em gerência e automação de redes de dados. Tem como foco a redução dos elevados custos operacionais observados nas empresas do ramo. Incubada desde março de 2006, a empresa recorre, principalmente, a sites e jornais. Congressos e encontros são raramente freqüentados. Os livros e revistas especializadas também foram indicados como fontes de informação. Quanto à oferta de informação pela incubadora tecnológica, o entrevistado esclarece que a ela fornece "informações sobre financiamento, capital de risco, programas do governo", mas (fazendo ressalva de que sua área é muito especializada) manifestou a percepção de que talvez os gestores da incubadora tecnológica não conheçam muito bem o negócio das empresas incubadas e, assim, deixariam a desejar no que diz respeito à oferta de informação adequada. O Conexão Gênesis foi apontado como um programa que permite o relacionamento com outros empreendedores e a troca de informações sobre como andam os negócios das empresas. Com relação ao informativo Panorama, o empreendedor diz que as informações divulgadas servem apenas para acompanhar o que se passa nas áreas de incubadora ou no ambiente específico da Incubadora Tecnológica do Instituto Gênesis.

Pré-incubada desde setembro de 2004 e incubada desde março de 2006, a empresa gama atua na área de petróleo e gás, com pesquisa e desenvolvimento de tecnologias inovadoras em sistemas mecânicos complexos e prestação de serviços. Como o mercado da empresa é específico para petróleo e gás, o responsável esclarece que "obtemos informações junto ao próprio meio e, também, em feiras e eventos”. Devido à especificidade desse mercado, o entrevistado acredita que a incubadora tecnológica pouco tem contribuído para a oferta de informação específica ao seu negócio, ressalvando que "sempre que surgem notícias novas, alguém da incubadora nos repassa, de imediato". O empreendedor diz só conhecer o informativo Panorama dentre os canais de comunicação da incubadora, e o considera como o mais utilizado pela sua empresa. Revistas do meio de petróleo e gás são outras fontes citadas como meio de obter informação útil para o seu negócio. Apontou, também, como úteis informações de "feira e eventos, seminários e palestras, além da informação de editais do governo, que é muito importante". 
Os resultados das entrevistas com as empresas já graduadas foram resumidos no quadro 1 .

é um espaço em que empreendedores, tanto da Incubadora Tecnológica quanto das incubadoras Cultural e Social da QUADRO 1

Resultados das entrevistas: empresas graduadas

\begin{tabular}{|c|c|c|}
\hline $\begin{array}{c}\text { Variáveis do roteiro } \\
\text { de entrevista }\end{array}$ & Empresa Delta & Empresa Ômega \\
\hline Tempo de incubação & 4 anos & 3 anos \\
\hline $\begin{array}{l}\text { Benefícios com a } \\
\text { incubação da empresa }\end{array}$ & $\begin{array}{l}\text { Proximidade com a PUC-RJ; } \\
\text { serviços de imprensa; recursos } \\
\text { humanos }\end{array}$ & $\begin{array}{l}\text { Apoio em serviços jurídicos, } \\
\text { assessoria de imprensa, recursos } \\
\text { humanos especializados }\end{array}$ \\
\hline $\begin{array}{l}\text { Fontes de informação } \\
\text { sobre o mercado }\end{array}$ & $\begin{array}{l}\text { Participação em eventos; revistas } \\
\text { especializadas }\end{array}$ & $\begin{array}{l}\text { Newsletter da IT, Internet, jornais, } \\
\text { revistas, eventos }\end{array}$ \\
\hline Contribuição da IT & $\begin{array}{l}\text { Aprendizado sobre } \\
\text { empreendedorismo }\end{array}$ & $\begin{array}{l}\text { Rede de relações com outras } \\
\text { empresas }\end{array}$ \\
\hline $\begin{array}{l}\text { Canais de comunicação } \\
\text { da IT que conhece }\end{array}$ & $\begin{array}{l}\text { Não nomeou (cita que, na sua } \\
\text { época, a comunicação era maior } \\
\text { com a PUC-RJ do que com a IT) }\end{array}$ & $\begin{array}{l}\text { Newsletter, portal do IG e eventos } \\
\text { do IG }\end{array}$ \\
\hline $\begin{array}{l}\text { Canais de comunicação } \\
\text { da IT que mais } \\
\text { utilizava }\end{array}$ & $\begin{array}{l}\text { Não nomeou (cita que ainda tem } \\
\text { acesso às notícias) }\end{array}$ & Não nomeou (cita a newletter) \\
\hline $\begin{array}{l}\text { Opinião sobre o } \\
\text { processo de incubação }\end{array}$ & Indicaria a IT para um amigo & $\begin{array}{l}\text { Foi um caminho natural na sua } \\
\text { história na PUC-RJ }\end{array}$ \\
\hline Comentário & $\begin{array}{l}\text { O mais importante foi aprender } \\
\text { sobre empreendedorismo }\end{array}$ & $\begin{array}{l}\text { A IT poderia conhecer mais sobre } \\
\text { os negócios das empresas } \\
\text { incubadas }\end{array}$ \\
\hline $\begin{array}{l}\text { Tipo de informação } \\
\text { que considera útil para } \\
\text { a empresa }\end{array}$ & $\begin{array}{l}\text { Sobre inovação tecnológica, } \\
\text { concorrências [editais] e cenários } \\
\text { tecnológicos no exterior }\end{array}$ & $\begin{array}{l}\text { Sobre editais do governo, mercado } \\
\text { de software, gestão do } \\
\text { conhecimento, economia } \\
\text { brasileira, grandes players, } \\
\text { concorrentes }\end{array}$ \\
\hline
\end{tabular}

Fonte: GONÇALVES, 2006, p.96

\section{Considerações finais}

O período de observação e participação na Incubadora Tecnológica do Instituto Gênesis foi extremamente valioso para incorporarmos um pouco do cotidiano e do comportamento dos empreendedores. Pudemos ter acesso a alguns dos canais de comunicação da informação utilizados nesse ambiente e obtivemos um retorno sobre o papel no processo de incubação das empresas, por meio da opinião dos empreendedores da incubadora escolhida. Contudo, foi possível observar que os empreendedores não chegam a formar o que Wenger (2000) denomina "comunidades de prática”*, configurando mais um grupo de usuários de sistemas de informação (mediados pelo Instituto Gênesis) do que de produtores de conhecimento.

No programa Conexão Gênesis, por exemplo, idealizado pelo Departamento de Comunicação do Instituto Gênesis, percebemos quanto a oportunidade do encontro entre empresas e seus empreendedores é importante para o crescimento intelectual dos participantes. O programa

\footnotetext{
* Para o autor, as comunidades de prática consistem em pessoas que estão ligadas informalmente, assim como contextualmente, por um interesse comum no aprendizado e, principalmente, na aplicação prática
}

PUC Rio, compartilham informações sobre seus negócios e têm a chance de ouvir sugestões de especialistas e consultores de diversas áreas. É uma nova cultura que chega às incubadoras e que permite a transferência de informações para quem demanda tecnologias de produção e gestão.

O Programa Conexão Gênesis é um exemplo de como a incubadora pode ser vista na perspectiva de uma unidade de transferência de conhecimento (BARRETO, 1999). A equipe do Departamento de Comunicação do Instituto Gênesis mostra-se interessada em criar canais que permitam aos empreendedores e ao público da universidade interagir sobre problemas tecnológicos e possíveis soluções, com a ajuda da informação. No caso do informativo Panorama, para alguns empreendedores a formação jornalística da equipe não parece ser suficiente para que a demanda de informação vinda das empresas e seus empreendedores seja atendida. Sentem falta de especialistas em suas respectivas áreas de atuação, para dar suporte ao negócio de cada empresa.

Os canais de comunicação eletrônicos, que envolvem as trocas de mensagens, o portal do Gênesis e a extranet, bem como os encontros informais, foram destacados pelos entrevistados como fundamentais no processo de transferência da informação. A incubadora tecnológica é percebida como relevante, em seu papel de facilitar a transmissão do conhecimento e ofertar informação ao público usuário. A possibilidade de interação com profissionais competentes também foi apontado como um canal de informação. A realidade descrita revela o que Araújo (1978) já percebera, quando afirmou que os canais informais são as principais fontes de informação no ambiente tecnológico.

Todos os entrevistados ressaltaram o valor de sua empresa haver sido incubada ou de terem um dia participado do processo de incubação, considerado um diferencial em sua trajetória no mercado. A ligação com a incubadora não 
termina após a empresa receber a graduação, e muitas vezes ela dá suporte às empresas e empreendedores após a incubação, o que representa um valor inestimável no mercado competitivo da tecnologia. Percebemos, na observação e nas entrevistas, que os empreendedores demandam informação e que a incubadora tecnológica tem contribuído para gerar estoques de informação. A busca por informação é facilitada porque a Incubadora oferece a divulgação de fontes onde informações relevantes podem ser encontradas.

Chegamos à conclusão de que na Incubadora Tecnológica do Instituto Gênesis, tal como em uma unidade de transferência de conhecimento, a informação é vista como geradora de conhecimento. Observamos também que a incubadora valoriza a informação que circula em canais informais, considerados como altamente eficientes pela característica de comunicação direta entre a fonte e o usuário. E que, embora não prejudiquem o processo de comunicação, existem barreiras na transmissão da informação: dos tipos classificados na literatura, identificamos no campo da pesquisa aquelas que se referem ao tempo e à terminologia, bem como as de capacidade de leitura, de responsabilidade, de consciência e conhecimento da informação.

Na nossa jornada de investigação, observamos que a informação tornou-se fator primordial para as empresas se desenvolverem, adquirindo as condições básicas para entrar no mercado competitivo. Caberá aos gestores das incubadoras de empresas criar as oportunidades e os canais de comunicação para produzir e transferir estoques de informação para os usuários que deles necessitam, na sociedade. Quanto aos empreendedores, estes serão os responsáveis pela transformação da informação em conhecimento e inovação, de modo a alcançar maior vantagem competitiva.

Artigo submetido em 16/10/2007e aceito em 03/04/2008.

\section{REFERÊNCIAS}

ALBAGLI, Sarita; MACIEL, Maria Lúcia. Informação e conhecimento na inovação e no desenvolvimento local. Ciência da Informação, Brasília, v. 33, n. 3, p. 9-16, set./dez., 2004.

ANPROTEC. Agenda das cidades empreendedoras e inovadoras: idéias e propostas para prefeitos que querem gerar emprego e renda promovendo o desenvolvimento sustentável de suas cidades. Brasília, 2004. Disponível em: <http://www.anprotec.org.br/arquivo-pdf/ anprotec $\% 20$ prefeitos.pdf $>$. Acesso em: 19 de maio de 2006.

. Panorama 2005: relatório. Disponível em: <http://www.anprotec.org.br/ArquivosDin/ Panorama_2005_pdf_11.pdf $>$. Acesso em: 2008.

ARAÚJO, Vania Maria Rodrigues Hermes de. Estudo dos canais informais de comunicação técnica: seu papel em laboratórios de pesquisa e desenvolvimento, na transferência de tecnologia e na inovação tecnológica. 1978. Dissertação (Mestrado em Ciência da Informação) IBICT - UFRJ, Rio de Janeiro, 1978.

. Novas competências para os profissionais da informação. In: COLÓQUIO DE BIBLIOTECÁRIOS, 7., 2001, México. Preprint: resumo da participação em mesaredonda... México: [s.n.], 2001.

. Papel do profissional da informação em uma sociedade em mudança. Ciência da Informação, Rio de Janeiro, v. 15, n. 1, p. 11-3, jan./jun. 1986.

BARRETO, A. de A. A eficiência técnica e econômica e a viabilidade de produtos e serviços de informação. Ciência da Informação, Brasília, v. 25, n. 3, p. 405-414, 1996.

- A oferta e a demanda da informação: condições técnicas, econômicas e políticas. Ciência da Informação, Brasília, v. 28, n. 2, 1999.

BEAL, Adriana. Gestão estratégica da informação: como transformar a informação e a tecnologia da informação em fatores de crescimento e de alto desempenho nas organizações. São Paulo: Atlas, 2004.

BERMÚDEZ, Luís Afonso. Incubadoras de empresas e inovação tecnológica: o caso de Brasília. Disponível em: $<$ http://ftp.unb.br/pub/download/ipr/rel/parcerias/ 2000/1757.pdf>. Acesso em: 01 maio 2006.

CARVALHO, Luis Felipe; DIAS, Carolina. Panorama Mundial de Incubadoras. In: ARANHA, J. A. S. (Org.). Modelo de gestão de incubadoras de empresas: implementação do modelo. Rio de Janeiro: Rede de Incubadoras do Rio de Janeiro, 2002.

CLEMENTE, Armando. Modelo de gestão para incubadoras de empresas: uma estrutura de indicadores de desempenho. Rio de Janeiro: Rede de Incubadoras do Rio de Janeiro, 2001.

DIAS, Carolina; MARUJO, Marina; SIMÕES, Alessandra. Descrição do modelo de gestão. In: 
ARANHA, J. A. S. (Org.). Modelo de gestão de incubadoras de empresas: implementação do modelo. Rio de Janeiro: Rede de Incubadoras do Rio de Janeiro, 2002.

FREIRE, Gustavo Henrique de Araújo. Ciência da Informação: temática, histórias e fundamentos. Perspectivas em Ciência da Informação, Belo Horizonte, v. 11, n. 1, p. 6-19, jan./abr. 2006.

. Comunicação da informação em redes virtuais de aprendizagem. 2004. Tese (Doutorado em Ciência da Informação) - CNPq/IBICT - UFRJ/ECO, Rio de Janeiro, 2004.

FREIRE, Isa Maria. Barreiras na comunicação da informação tecnológica. Ciência da Informação, Brasília, v. 20, n. 1, p.54-54, jan./jun. 1991.

LODI, João Bosco. A entrevista: teoria e prática. São Paulo: Pioneira, 1974.

MARCHIORI, Patrícia Zeni. A ciência e a gestão da informação: compatibilidades no espaço profissional. Ciência da Informação, v. 31, n. 2, p. 72 79, maio/ago. 2002.
MARCONI, Marina de A.; LAKATOS, Eva M. Técnicas de pesquisa. São Paulo: Ed. Atlas, 5ed. Ver. Ampl, 2002.

MIRANDA, Antonio; SIMEÃO, Elmira. Transferencia de información y transferencia de tecnologia em el modelo de comunicación extensiva: la Babel.com. Información, Cultura y Sociedad, Buenos Aires, n. 10, p. 27-40, 2004.

MORAES, Alice Ferry de. O uso de estratégias na transferência de informação nos vídeos de saúde. 2004. Tese (Doutorado em Ciência da Informação) - CNPq/IBICT UFRJ/ECO, Rio de Janeiro, 2004.

STAINSACK, Cristiane. Estruturação, organização e gestão de incubadoras. 2003. Dissertação (Mestrado em Tecnologia) - Centro Federal de Educação Tecnológica do Paraná, 2003.

THIOLLENT, Michel. Metodologia da pesquisa-ação. São Paulo: Cortez, 2005.

WENGER, E. C.; SNYDER, W. M. Communities of practice: the organizational frontier.

Harvard Business Review, p.139-145, Jan./Feb. 2000. 